\title{
Una aproximación al lógos heracliteo
}

\author{
GIUSEPPINA GRAMMATICO \\ Universidad Metropolitana de Ciencias de la Educación \\ Santiago de Chile
}

\begin{abstract}
RESUMO: No trabalho analisam-se em primeiro lugar os significados da palavra lógos, sendo esta análise a base que sustenta a indagação sobre a natureza do lógos heracliteano. Este parece ser, de acordo com a sua etimologia, a causa, o semelhante e a revelação, e parece coincidir com o Ser.

É necessário, entretanto, ratificar, à luz de certos fragmentos-chave, a verdade de tais afirmações. São considerados "chave" os fragmentos $2,72,123,115,45,1$. Al aparecem o adjetivo xynós, "comum"; a frase hós málista dienekôs homiloasi, "aquele com o qual os homens têm trato mais continuamente"; a palavra phýsis, "natureza"; os atributos auxôn, "que se acrescenta", e bathýs, "profundo"; e o binômio hèn-pánta, "um - tudo". Examinadas atentamente, todas estas expressões oferecem argumentos que confirman a justeza da hipótese inicial.
\end{abstract}

PALAVRAS-CHAVE: Lógos, Heráclito, filosofia grega, Grécia.

ouk emoâ allà tô lógou akoúsantas homologeîn sophón estin hèn pánta

[ Fr. 50]

\section{Los sentidos del término lógos}

De los significados del término logos mencionados en el Lexicon (LiddellScott, 1985): "Cómputo, relación, esposición, pensamiento, expresión, aserción, contenido, lenguaje, palabra divina", ninguno corresponde a la primera acepción del verbo légo (B), "reunir, recoger". Casi todos ellos, sin embargo, la suponen como un soporte sin el cual no quedarían debidamente fundamentados. Los primeros dos, el de cómputo o cuenta y el de relación o correspondencia, que son técnicos y específicos a partir del siglo cuarto a.C., en el tiempo de Heráclito pueden ser pensados menos racionalmente y más vitalmente. Y del mismo modo pueden ser pensadas las primeras dos acepciones de légo: "recoger/reunir" y "computar/enumerar". Es importante volver a descubrir el sentido originario de las 
palabras, el que tenían antes de que el tiempo las desgastara y los hombres las empobrecieran y trivializaran. Sólo de este modo es posible rescatar su valor primigenio y percatarse de su intensidad y poder suscitativo. En el contar radical que cobija la valia de lo contato (que es lo que se "tiene en cuenta", pues de otro modo no se contaría), y en el recoger radical que implica la intención que mueve a realizarlo, están: la elección de lo que habrá que recoger y la ponderación de todo elemento concomitante que permite juzgar si vale o no la pena llevar a cabo el trabajo. La primera implica una estimación que concierne las raíces de lo estimado. La segunda supone una re-unión que desafía la labilidad y la dispersión de las cosas que sólo si son reunidas en nosotros adquieren una firmeza y valor real.

Son ese contar y ese recoger radical que originaron luego, y van a seguir originando, el contar y el recoger específicos: el técnico, el científico, el doméstico, el laboral, y todos los otros posibles.

La última acepción de lógos, que parecería, a menudo, en Heráclito la más apropiada, es un término filosófico tardío empleado por Plotino, Plutarco y Filón, y se encuentra también en el Corpus Hermeticum. Ella fue y continúa siendo largamente usada en la tradición cristiana, y tiene sus antecedentes, indirectamente, en la divine utterance, id est, en la voz del oráculo que traía a presencia la palabra del dios.

Las siete acepciones restantes se colocan en el ámbito de lo que aclara, ilustra, muestra, expone y relata. Se refieren a la exposición o explicación de una reflexión, de una teoría, de una normativa o de cosas afines. La palabra no se limita nunca a ilustrar la parte vocal, externa, de la exposición, o por lo menos nunca ilustra solamente aquélla. Aun cuando significa "término", siempre se trata de un término que expresa una razón, una cosa concreta. Su enunciación comporta la reflexión y el resultado que en ella se adensá y ordena, desembocando en la expresión. En el Lexicon el lógos heraclíteo está ubicado en las diferentes secciones de las acepciones tercera y cuarta. El sentido de "argumento", atribuido, con reserva, precisamente al fragmento 50 , no satisface si se entiende el término en el modo en el cual ahora lo entendemos; se aclara, en cambio, si lo consideramos como algo resplandeciente e iluminador, que es lo que sugiere su étimo. Su raíz es, en efecto, la de argós y significa "de un blanco brilhante".

El término lógos posee una dinámica interna que Heráclito debió percibir, o al modo de una synapsis musical (Shipton, 1985), o al modo de una procesión circular (Heidegger, 1958), o al modo de una oposición bifrontal del tipo lógosérgon. Las tres hipótesis son sugestivas y ninguna de ellas es excluyente. Si optamos por la última, se nos plantéa de inmediato la pregunta: No será érgon, la cosa concorde y discorde con respecto al lógos que la hace patente, algo así como la "puesta en obra" del lógos mismo? Y qué puede ser esa puesta en obra del lógos sino la concentración y espesura del mismísimo Ser?

\section{Naturaleza del lógos}

Tras el análisis del término estamos en condición de iniciar la indagación de la naturaleza de aquello al cual el término remite. No parece atisbar un lógos a la vez originante, reuniente y develante, y nos parece ver que, en el comienzo, estas tres instancias debieron coincidir. Intentaremos entonces profundizar la na- 
turaleza del lógos en las tres dimensiones, y estudar sus imbricaciones. Puesto que lo primordial y originante se sitúa en el comienzo de todas las cosas, empezaremos por la primera dimensión.

Heráclito pertence y a la vez no pertenece al grupo de los pensadores jónicos que buscan la arkhé. Su arkhé es un elemento, el fuego, que, sin perder las connotaciones físicas, reviste otras que no lo son. Es pŷr phrónimon o lógos pýrinos. Posee la determinación del agua de Tales y la indeterminación del ápeirón de Anaximandro, y anticipa ciertos rasgos del noûs de Anaxágoras. Es un elemento que, debido a esas carcaterísticas suyas, se distancia de todos los otros. $O$ es mucho más que un elemento. Fuego inteligente o inteligencia ígnea, se constituye en regla, principio, razón, fundamento y fórmula del universo, ya sea el que llamamos físico o metafísico, ya el que llamamos ético $o$ estético, ya el que llamamos gnoseológico o lingüístico. Y como tal ha de ser reconocido. Por eso el lógos del fragmento 50 exige el homologêin: quiere ser visto y descubierto en su auténtico ser; seguido, admirado, entendido y proclamado: visto como constitutivo físico del mundo, vislumbrado como principio ontológico, seguido como razón normativa, admirado como armonia suprema, entendido como inteligência rectora y celebrado como desocultamiento sin fin.

Este lógos, principio y fundamento del ser, se explica, de acuerdo a los dos significados principales de légein, como reuniente y develante. Estas dos acepciones están de tal manera ensambladas una con la otra, que resulta casi imposible considerarlas aisladamente. Ya hemos aludido, en el intento de graficar el movimiento del lógos, a una circularidad que abarca sus distintas etapas, o a un enfrentamiento de fuerzas opuestas y concomitantes. Buscaremos hacer luces sobre una y otra, explorando la natureza del recoger y el revelar.

El recoger supone un propósito y una ponderación inicial; un propósito que contiene la intención y la finalidad de la acción, una ponderación que coloca en los platos de la balanza los pro y los contra, dando peso (pondus) a lo que verdaderamente lo tiene y minimizando lo que no merece la pena; y supone la consigiente búsqueda. Comprende el divisar lo buscado, el cogerlo, el levantarlo, el anuar cierta cantidad de especies, el seleccionarlas, el escoger aquellas que, tras una observación cuidadosa, aparecen poseedoras de los requisitos exigidos, procediendo por relaciones, correspondencias, proporciones y analogías, y el comunicar el término y el éxito de la recogida mediante la ex-posición y la celebración. El propósito, implicado, como vimos, en la palabra lógos ${ }^{1}$, es el resorte de toda la serie de acciones que acabamos de enumerar, y es acompañado por una buena disposición y una firme resolución. Obedece a una intención, o sea, a una determinación de la voluntad en orden al fin, y su realización está subordinada a la atención que es capaz de prodigarle. Intención y atención son fuerzas que mueven, y de ellas resultan ciertas operaciones. No se trata, o no es necesario que se trate, de operaciones físicas. Hay cosechas del espíritu en las cuales todas las operaciones son movimientos del alma, inward debate of the soul, que no exigen cambio de lugar ni fatiga corporal. Y son las cosechas más valiosas. El levantar al sol una haz de espigas o unos racimos de uva equivale a coger el ser de lo "siente" en su emergencia y en su esplendencia, lo suficiente para contemplar sus rasgos, escuchar sus latidos, darle un nombre y guardarlo en el corazón. El hecho de que esto llegue a acontecer depende de dos condiciones: por un lado, el deseo del Ser de mostrarse, que se concreta en el empinarse de la cosa que quiere ser "notada"; 
por el otro, el deseo de quien la ha encontrado y recogido, de hacer a otros partícipes del hallazgo.

El recoger se mueve entonces entre dos mostraciones, la del ser, o, si queremos usar un lenguaje concreto, de la "cosa" que se muestra, y la de quien la descubre, y, gozoso por el descubrimiento, la muestra. Porque el mostrar tiene un aspecto reflexivo en el cual se repliega sobre lo mismo que muestra, mostrándose a sí mismo, y uno transitivo en el que tiene como destinatario a otro que está fuera de él y del cual reclama el asombro.

El lógos se recoge y recoge, revela y se revela. Es la ex-posición de lo reunido, es decir, el translado de la ausencia del ocultamiento a la presencia de la "de-velación", y su confluencia en la expresión que hace posible su conservación y su cobijamiento en la memoria, salvándolo de la oscuridad y situándolo en la luz.

Llegados a este punto nos preguntamos: Guarda, el lógos del fragmento 50, la memoria de ese deroulement y de todas sus implicaciones? Es difícil decirlo. Pero si admitimos, como lo haremos provisoriamente, que su despliegue es el hèn-pánta final, entonces es muy probable que estemos en lo cierto. "Uno-todo" es la fórmula más amplia y a la vez más escueta de identificar al ser en su globalidad. Al atribuir esa expresión al lógos, como lo que le atañe por ser tal, in-sumimos en él las múltiples formas del eînai reconducibles a unidad. Y el eînai, en cuyo interior se conjugan siempre, en el pensar de Heráclito, un pareînai y un apeînai, pasaria desapercibido si no se llevara a cabo, etapa tras etapa, ese proceso destinado a sorprenderlo, a comprenderlo y a mostrarlo. Quizás poderíamos desde ya atrevernos a pensar que lógos es el Ser mismo en el acto de apartarse del ocultamiento e irrumpir en la luz; el Ser que infatigablemente sale de sí y regresa a sí, se dispersa y se aúna, siguiendo un compás musical que él solo conoce. Y no el ser de ésta o aquélla entre las cosas que son, sino el Ser "en sí", uniente y develante, que se oferece al entendimiento como hèn pánta y reclama nuestro. homologeîn. El Ser "siente".

\section{El lógos xynós (Fr. 2)}

Nos explicaremos mejor la naturaleza de esa facultad unitiva del lógos, si interrogamos el fragmento 2 y volvemos a hacernos la pregunta: Qué es el lógos? El texto dice así:

dió dề hépesthai tôi xynói, tôu lógou d'éontos xynoû zóousi hoi polloi hos idian ékhontes phrónesin.

Pues conviene seguir lo común; sin embargo, siendo, el lógos, común, vive la mayoría de la gente como si tuviera una phrónesis propia.

Aqui el lógos tiene el atributo xynós que significa "común, general, público, indiviso, igual, de todos". El adjetivo es la ampliación de la preposición xyn que expresa unión, acompañamiento, participación, extensión, tendencia a establecer contactos $^{2}$. El ser xynós es un ser unitivo y comunicante. Es lo focal del lógos. La raíz de légein, el homós de homologeîn y el xyn de xynós están perfectamente alineados. $X y n$ indica una inclinación a la unión que coordina los elementos activos 
del texto que estamos examinando, sin estar presente visiblemente en él. Estos son: el lógos, que actúa como xynós, Heráclito que es su mejor intérprete, y todos aquellos que han sido sometidos a la prueba de su mostración. Se trata de una experiencia totalizante: la experiencia viva del con como "lo uniente", que se afirma sobre el sin, "lo excluyente", apartándolo pero no negándolo, dejando que sea visto como signo de "indigencia de ser". La experiencia de lo Uno, que es en la medida en que se une con la globalidad de las cosas que son. Un lógos tdios es inconcebible, pues negaria el ser mismo del lógos, de por sí propenso a la relación, al contacto, a la comunicación y finalmente a la de-velación. El termino xynós, "común", parece simple de entender, casi obvio. Es común el aire que respiramos, el mundo en. que vivimos, el ser que en nosotros palpita. En el normal desenvolvimiento de lo que acaece, es común el choque de cosas opuestas. Todos tienen parte en lo común, pero lo común no es exclusivo de nadie ni de nada. Común es, en efecto, lo contrario de privado, particular, propio. Hay más: eso que es común no deja de ser todo-lo-que-es por el hecho de repartirse entre la generalidad de los seres. Mantiene, en todos, lá totalidad de sus propiedades. Es igual en todos; aunque en cada uno "aparezca" de un modo distinto. To xynón consigna la existencia a nivel primario de una potencialidad de enlace colectivo que confiere unidad $-y$ organicidad a la multiplicidad de los entes. Dicho de lógos, xynós no hace sino ratificar y acentuar su significado.

a. Si lógos es "lo uniente", el adjetivo no podría ser más adecuado: lo uniente tiende a relacionarse, se estira hasta tocar lo otro para juntarse con él y formar, juntos, una misma cosa. Al ejercer su fuerza unitiva, conduce a presencia en la unidad aquello que por sí solo no alcanzaria a tener una entidad propia. Como lo uniente unifica, lo común "comunica", en el sentido de "comuniza", pone en común, ata con lazos firmes las cosas que sin él estarían dispersas, trabándolas de tal modo que integren y realicen el ser de lo uno. Se da así una com-unión de todo, cada cosa participando, de acuerdo a su propio ser, de la armonía total.

Xynós no es aquí un simple atributo. Retrata y define el ser del lógos, un ser cohesionante, relacionador, comunitario.

b. Si lógos es "lo develante", el adjetivo le calza como el guante a la mano. De-velar es mostrar y mostrarse, cualquiera que sea el modo de esa mostración. El develamiento exige un tú atento, admirante o escuchante, al cual cautivar, con el cual asimilarse, en el cual asomarse. El asombro translada lo develado al interior de aquel que asiste al desocultamiento, a la epipháneia, a la. aparición : en el contacto se hace viva la presencia y nace la expresión que celebra esa presencia. Esta presencia tiene la misma naturaleza de lo uniente : enlaza signos visivos o sonoros hasta formar un "relato", gráfico o vocal, capaz de evocar con irrestricta fidelidad el objeto de la develación.

Tampoco aqui xynós es un simple atributo. Retrata y define el ser del lógos : un ser develatorio y comunicante.

c. Si Lógos es Inteligencia rectora que dispone, organiza y relaciona todo en orden a un proyecto concebido en arkhêi, acuciosa y juiciosamente, habrá que admitir la posibilidad de que xynós haya sido "sentido" por Heráclito como fusión de $x y n$ y nó $^{3}$, o sea, dotado de facultad intuitiva. En este caso el lógos aúna presencias que se atisban más que verse y oírse, cuyo ser se inscribe en una zona a la cual sólo se accede mediante el nóos. Un lógos-gnóme, que reconoce y regula, que juzga y decide en el principio del principio, no puede no ser $x y n \delta s$, entendiendo el término en el sentido antes mencionado. 
Sólo en unión con el nóos puede realizar su ser discerniente y deliberante.

En los tres casos el $x y n$ intensifica la fuerza de la raíz leg. Entendiendo al lógos como xynós, veremos asomarse en él la concatenación de todas las cosas, vislumbraremos la asunción de lo múltiple, con todas sus diferencias, en un Uno que discierne, reúne y revela. Concebiremos a un lógos que, siendo principio y desde el principio, sale a buscar las cosas que reconoce y en las que se re-conoce, las saca de sus escondrijos, las levanta a la luz para despertar su brilho, las expone a la vista de todos, para volver finalmente a custodiarlas bajo su alero. A un lógos que recorre en las dos direcciones, desde dentro hacia fuera y viceversa, el camino del ser, y junto con el ser de las cosas, saca del escondimiento, instala en la claridad, guarda al amparo a su propio ser. Es así como podemos comprenderlo no del todo separado de las cosas; como podemos pensarlo en ellas y pensarlas en él; como también podemos atrapar su presencia en ese salir y entrar, en ese buscar y traer, en ese ir y venir. En su ser deviniente.

\section{El lógos hôi homiléousi (Fr. 72)}

Aunque logremos entender al lógos como xynós, no nos será fácil imaginàrlo. Para que nos respalde en esta tarea, acudamos al fragmento 72 en el cual Heráclito ha dibujado sus rasgos con mayor precisión. Dice así:

\section{hôi málista dienekéos homiléousi, lógoi tôi tà hóla dioikoúnti, toútoi diaphérontai}

de aquél con el cual más continuamente están en contacto, del lógos que rige la totalidad de las cosas, de ése se distancian ${ }^{4}$.

No podemos no convenir que ésta es una definición del lógos particularmente acertada. Ademàs de ser muy bella, ella corrobora y explica la expresión lógos xynós del fragmento anterior. Y otra vez nos obliga a preguntarnos : Qué es o quién es el lógos; para que Heráclito pueda aludir a él en estos términos? Quién es aquél o qué es aquello con lo cual siempre nos encontramos, en cuya compañia estamos todo el tiempo, al cual a veces nos enfrentamos, con el cual otras veces consentimos, con el cual, de uno y otro modo, sin cesar entablamos relaciones? Parece ser algo o alguien que está fuera de nosotros pero del cual no podemos desentendermos porque nos sujeta a él una singular conexión. ¿Quién es o qué es sino el Ser mismo de lo uniente, que nos ad-viene, por cuyo contacto somos, al cual nos resistimos en un afán de libertad que nos conduce a nuestra propia negación, al cual siempre volvemos, atraídos por esa afinidad que nos lo hace connatural?

El ser de lo uniente se vuelve como una constricción para los hombres ignaros del sentido de su estar en el mundo. Ellos se encuentran, con respecto a él, en el medio (metaxý) entre el xyn y el antí; tironeados por fuerzas contrarias que parecen generarse una de otra. Están en el corazón de lo enantion. Esta situación se origina por la posición frontal en que vienen a hallarse en relación 
con el lógos y que puede resolverse en amigable concordia o en hostil resistencia. En cierto modo, se sienten acosados por él y esto los agobia. Sorprendemos al lógos como el Ser-al acecho-de-los-entes. Su facultad unitiva lo hace perennemente vigilante, atento a que no se le escape la presa. Puesto que hay una multitud de seres, en especial los humanos, potencialmente "sientes" y casi todos subyacen a la tentación de desvincularse de lo xynón y de permanecer en el sopor de la ausencia, el logos se somete a la tarea sin fin de llamarlos, convocándolos para que participen en el ser, y de mantenerlos "presentes" en él. Siendo, por así decir, familiar suyo, el lógos se les presenta a los hombres como extranjero (xénon) : y sin embargo, donde quiera que uno mire, todo está bajo sus cuidados. Ese rasgo de familiaridad es ilustrado por el participio dioikounti que se aplica al que gobierna, y en el cual aún se siente la presencia del ốkos que indica la casa y quienes habitan en ella. Bajo la tutela del lógos no sólo están los hombres : la imagen colectiva de tà hóla como "su familia" confirma la justeza de la interpretación del lógos como lo uniente en su ser o como el ser de lo uniente. Lo uniente inhabita tó hóla, y, mientras esté allí, todos los entes se mantendrán en el ser.

De qué manera el fragmento 72 nos ha ayudado a entender la natureza del lógos ? Diríamos que mediante el acierto que constituye el empleo del verbo homiléo en contraposición con el diaphérontai final. Aunque sus significados sean parecidos, homiléo es más fuerte que el symphéro y el symphéromai que Heráclito usa en situaciones semejantes, y además conlleva el eco del homós, "par, el mismo, común, semejante, igual" ${ }^{16}$ que remite al homologêin del fragmento 50, nuestro punto de partida, y ratifica el xynós como calidad propia del lógos.

El choque entre la actitud distante de los hombres, que en realidad es calculada y responde a la tozudez de la idía phrónesis, y el afán protector del lógos, origina una dualidad que habrá que inscribir en el marco de las oposiciones heraclíteas, y que terminará por ser beneficiosa; como toda dualidad. El lógos, a la luz del fragmento 72 , adquire un nuevo rostro.

En el fragmento 50 quiere ser entendido, en el fragmento 2 quiere ser seguido, en el 72 quiere simplemente ser querido: quiere que, al tropezar con él, los hombres lo reconozcan como no-forastero, como de-la-casa.

Pero volvamos a hacer la pregunta esencial : Qué es eso, o quién es ése al que se puede identificar como "aquel con el cual más continuamente los hombres están en contacto? Quién podría ser sino el Ser? Sólo al Ser nadie ni nada puede sentirse ajeno, porque lo que es ajeno al Ser es mera ausencia, y no se puede ni tropezarse, ni fastidiarse, ni trabar amistad con alguien que no es. Ante el vigoroso y concreto pensamiento del efesio, el Ser toma cuerpo en el lógos unificante y fecundo. La experienncia vital del contacto está en el homilousi con toda su fuerza. Todo contacto es fecundo, y por él algo viene a la luz. El trato con el lógos pone las cosas en el ser. Homiléo continúa y corona el proceso atisbado en el enkyréo del fragmento $17^{7}$. Del encuentro nace la unión, llámese ella amistad, amor, ad-similación, adhesión, combinatória. Y se produce un ser nuevo desafiando la dualidad y la distancia. Pues habrá que colmar esa distancia para que el encuentro dé sus frutos, sin olvidar no obstante que esa misma distancia, al mostrarse como oposición, mueve a la vida: lo xénon se torna íntimo y algo nuevo florece. 


\section{El lógos - physis (Fr. 123)}

La potencia de la imagen del verbo homiléo y la florescencia que le sigue al contacto cuando éste es íntimo y no superficial, nos remite al fragmento 123 donde el lógos está embozado, no tanto, sin embargo, que no sea posible divisarlo. El texto, críptico y muy bello, dice así :

\section{Phýsis krýptesthai phileéi}

La estructura interna de todo lo que es ama ocultarse

Phísis no es aquí sino un nombre del lógos, un nombre del Ser. Interroguemos el fragmento: ¿Qué puede significar ese deseo de permanecer en secreto? ¿Qué quiere decir philéi? ¿Cómo puede la phýsis querer ocultarse cuando su ser entero es desocultamiento? La germinación que instala las cosas en el ser aparece obedeciendo a un movimiento que conduce de lo secreto a lo abierto, de la léthe a la alétheia. ¿Cómo entiende entonces Heráclito esta phýsis kryptoméne? ¿Está aquí acaso encubierta la oposición en el interior de una única realidad "principial" ? Preguntémonòs por el ser de la phýsis. Es ella, dijimos, "ser germinante". Brota de honduras que se rehusan ser alcanzadas por el pensamiento, y de las que sólo sabemos que no tienen fondo. Su "aparecer" la coloca entre los phainómena; pero acerca de éstos no está demás preguntarse : ¿Se agotan, ellos, en eso que aparece? Son sólo lo que de ellos vemos? ¿O no es, eso que vemos, una especie de anzuelo para despertar nuestra curiosidad? ¿Qué hay detrás de ese " estar alli" ? ¿Más allá de esa presencia? ¿Qué es eso que se cela y parece hacerse tanto más inasible cuanto más sencillo y lozano se ofrece a la mirada? "Yerran los hombres en el conocimiento de lo visible", (tôn phanerôn), dice el filosofo en el fragmento 56.

Habrá que distinguir la phýsis de lo phanerón. La primera se extiende en la zona obscura en que acontece la gestación, el segundo en aquélla reverberante de la florescencia. No pueden desentenderse una del otro. El phainómenon que constituye lo visible (to phanerón) tiene una dimensión que se escapa a los sentidos: se afinca en la otra ladera de la luz, y es allí donde empieza a configurarse como lo-que-es. La phýsis, por su parte, contiene lo visible y lo invisible de cada cosa, $y$, en el acto de instalación de la cosa en la luz, se complace en mantener en secreto "eso suyo" que para ser advertido exige bien otros ojos, bien otros oídos, bien otra capacidad de intuición. La phýsis de cada cosa no es la cosa con todas sus notas, es la "esencia", la "estructura", la "constitución interna" de ella, y parece ponerse como un desafío para el dízesthai humano. Ella es el germinar y lo previo al germinar. Es lo que hace posible la germinación, lo que funda el ser germinante de cada cosa, lo que con-tiene el sentido profundo de ese germinar. En ella lo visible y lo invisible se tocan, se condicionan y justifican mutuamente. Son conjuntamente. Ese afán de celarse es deseo de proteger de ojos profanos lo más valioso de sí. Como por una suerte de estrategia, su ocultamiento invita al descubrimiento. Ella se entrega en la medida del interés, del esfuerzo, del deseo: lanza sus puentes y confía en que los hombres se atrevan a atravesarlos. Quietamente los espera. Y lo mismo hace el lógos. 


\section{El lógos aúxon y bathys (Fr. 115 y 45)}

Nos parece claro que, a pesar de la diferencia de las situaciones, los aspectos del logos que hasta ahora hemos examinado, se integran perfectamente uno al otro y encuentran su justificación en la interpretación del lógos como Ser. Estamos, sin embargo, conscientes de que tal interpretación puede ser objetada y de que necesitamos más argumentos para fundamentarla.

El fragmento 115, en el cual Heráclito habla del logos del alma, nos proporciona uno muy importante. El texto está entre los más admirados y dice:

\section{psykhês esti lógos heautòn aúxon}

Es propio del alma un lógos

que se acrecienta a sí mismo

Aqui lógos es intraducible si no se piensa" en el ser. Ni la "medida" de Mondolfo, ni el "criterio numérico" de Marcovich, ni el "intelecto" de Diels, ni el "discorso" de Capizzi, ni la "espressione" de Colli, para citar algunas propuestas, convencen del todo. Más plausible nos parece la traducción de Pasquinelli : "natura", en el sentido de "struttura intima", y la identidad "logos-fuego" de Gigon. Lo que nos interesa és escudriñar esa propiedad extraordinaria que Heráclito en este texto atribuye al logos del alma, el cual, como piensa Disandro (Disandro, 1969, p. 209), es espejo del lógos simplesmente tal. Se trata de la capacidad de acrecentarse a sí mismo, de extenderse y aumentar. Cabe preguntarse qué significa ese aumentar. En Homero el verbo aúxo es referido a sentimentos que se intensifican debido a fuerzas que vienen de los dioses. Heráclito, en cambio, no piensa en nada externo. Este es un acrecentarse "desde s $\tilde{r}^{\text {" }}$ y le pertence al alma: la del hombre vivo, pero también el alma universal, principio de todo.

Aristóteles habría pensado en Heráclito al decir: "Algunos creen que la natureza del fuego sea de por sí la causa de la nutrición y del crecimiento". El fuego parece, en efecto, el único entre los cuerpos o los elementos que "se nutre y crece ${ }^{\prime \prime}$. El alma sería para Heráclito una evaporación o exhalación ígnea, que, al salir de sí, comunica ser, además de alimentarse y crecer ella misma. Otro testimonio aristotélico nos recuerda que "Heráclito también sostiene que el alma es principio, puesto que es la exhalación por la cual pone junto en el ser (synistesin) todo lo otro" . Hay entonces una díada originaria alma-fuego pensada como soplo que tiene unidas todas las cosas. Es quizás para explicitar esto, que Heráclito atribuye al alma un logos, lo cual no es sino reconocer su "ser reuniente" ; y es por lo mismo que otorga a ese lógos la facultad de aumentar. Si entendemos bien el camino del pensamiento heraclíteo, el carácter unitivo del lógos es acorde a la capacidad del alma de "poner juntas en el ser" todas las cosas, capacidad que se - resuelve en un parenne acrecentamiento del ser y en una constante actualización de la unidad de la propia alma. Y es también acorde a su propia naturaleza ígnea que la hace aumentar a partir de sí. El fuego, en efecto, devora y unifica: su vida es la unificación de todo; llameando aplana y destruye lo otro que le es ajeno (xénon) y lo reconduce a lo que es de todo (xynón). Es acorde además a su naturaleza de soplo que sale de sí para luego volver a entrar en sí mismo, al modo del aliento, siempre igual y siempre otro "come el soffio d'aria nella cavità della zampogna"10. ¿De qué manera ejerce ese poder unitivo? Como se ha dicho, saliendo 
de sí y estableciendo un contacto directo con todas las otras cosas. El suyo es un salir de sí que parece, y en cierto sentido es, un. "perderse", pero que se torna a la vez en un "volver a sí" que parece, y en un cierto sentido es, un "recogerse". Gracias a ese contacto, como ya hemos visto, las cosas vienen a presencia, juntas una a las otras, y todas juntas al ser. Al volver, el soplo del lógos, dentro de sí, todo eso otro es entrado, por así decir, bajo techo, aumentando el caudal del ser reuniente ${ }^{11}$. Lo uniente sólo puede pensarse conjuntamente (háma) con lo disperso. ¿Podría haber lo disperso, si no hubiese lo uno? Desperdigadas e inmersas en la ausencia del ocultamiento, las cosas esperan el aliento del Ser que, alcanzándolas, las despierta y las coloca a la luz. El ritmo de la respiración (anapnoé) es un perfecto ejemplo del ritmo del lógos que se expande y'se recoge poniendo en el ser todo lo otro y acrecentándose con él ${ }^{12}$. Es así como el lógos desafía las leyes naturales y se sitúa en el ámbito de lo divino. Este, para Heráclito, excede toda medida, alimenta todo lo otro y siempre hay más ${ }^{13}$. El acrecentarse a sí mismo ininterrumpidamente da como resultado una ilimitada plenitud de șer.

Por otra parte, el lógos bathýs del fragmento 45 nos permite entender la otra cualidad atribuida por Heráclito al logos del alma, la profundidad, que es también interioridad. Bathý, en efecto, es lo que penetra, lo que se extiende y llega hasta muy dentro, lo que, cavando, alcanza lo más recóndito y se constituye como lo más intimo. Escuchemos el texto:
psykhês péirata iòn ouk dn exéuroio, pâsan epiporeuómenos hodón hoúto bathýn logon ékhei.
Poniéndote en marcha, no descubrirías los lindes del alma, aunque recorrieras todos los caminos, tan profundo logos ella tiene.

Bruno Snell dice, refririéndose a ese "ser bathy": "La rappresentazione della profondità è sorta proprio per designare la caratteristica dell'anima, che è quella di avere una qualità particolare che non riguarda lo spazio nè l'estensione, anche se poi siamo costretti a usare un'immagine spaziale per designare questa qualità a-spaziale. Con essa Eraclito vuole significare che l'anima si estende all'infinito, propio al contrario di ciò ch'è fisico" (Snell, 1963, p. 41). Y Carlos Disandro afirma : "Este peregrinaje es, en otros términos, un descubrimiento mitico de la absoluta interioridad del hombre"(Disandro, 1969, p. 209).

Aquí el ser reuniente del logos es pensado penetrando y actuando en honduras sin confines, como profundidad del ser que nunca toca fondo. El hombre sólo puede hacer experiencia de la profundidad, sumergiéndose en lo interior de su alma, en el abismo insondable de su ser. Es lo que Heráclito confiesa haber hecho, en el fragmento 101 :

\section{edizesámen emeoutón}

Me he buscado a mi mismo.

Es allí donde encuentra su propio "ser uno", pero es allí también donde encuentra las innúmeras cosas que a lo largo de la ruta ha ido recogiendo; recreando y haciendo suyas. Mucho antes de que Aristóteles reconociera que el alma es todas 
las cosas, Heráclito la ha pensado como un lógos profundo que se acrecienta a sí mismo, y la entendido ese lógos como la fuerza unitiva y fundante del ser.

\title{
7. El lógos eón aieí (Fr. 1)
}

Hemos dejado para el final el atributo más decidor, que no aparece en el fragmento 50 pero se deja entrever sin dificultad porque está allí implicado, y que en cambio está explícito en el fragmento 1 :

\author{
tou de lógou toud eóntos aiel \\ axýnetoi ginontai ánthropoi \\ kai prósthen è akousai \\ kal akoúsantes tò prôton \\ De este lógos siempre siente \\ resultan los hombres ser incomprensivos, \\ ya sea antes de haberlo oído \\ ya luego de haberlo entendido como lo principial ${ }^{14}$.
}

Analicemos la expresión toûde éontos aiet. ¿Por qué Heráclito dice "éste" hablando del lógos ? ¿Porqué habla de él como éontos aiế? ¿El aiel que sigue a éontos, se refiere a este último o al axýnetoi que viene inmediantamente después? ¿O se refiere a los dos? Nos parece más probable que se refiera a ambos. Heráclito sostiene aquí que los hombres no entienden al lógos ni siquiera después de haber hecho de él una experiencia plena. Esto le parece inconcebible en cuanto el lógos está ahí. Puede aludir a él diciendo: "Éste", y casi señalándolo con el dedo ${ }^{15}$. Justamente tras èl impacto de esa presencia viva expresada en el "éste", Heráclito lo define como eón, "el siente". Y como si eso no bastara, agrega el adverbio aiéi, "siempre", identificando así el Lógos como "el siempresiente". ¿Que significa "siente"? ¿Qué es "ser"? El diccionario nos dice : es "existir" en sentido fuerte; es "ser" como verbo-sustantivo, y con usos distintos de los que son propios de la frase nominal. Los bombres experimentan el ser y no conocen, de su contrario, sino aquello que se podría denominar "el negativo de la imagen". A pesar de que los campos semánticos del ser y del existir se toquen, "ser" es más que "existir" : es un existir desprovisto de límites, liberado del ex. Eón es aquí intransitivo: hay lógos; está ahí; "existe"; se ofrece al entendimiento. El lógos "es". Es terriblemente difícil definir el ser. Podemos pensar cualquier acción y cualquier estado, menos la "acción" y el "estado" del ser; y sin embargo ninguna otra acción y ningún otro estado podría concebirse y tendría sentido, si el ser no fuera. Es lo "previo" a todo, la conditio sine qua non de todo. No se puede ser de "ningún modo", si no se es. Y tampoco se puede hacer nada. Ser es lo primero, to prôton. Por eso Heráclito llama al lógos : "siente". Si no entendemos eso, no entendemos al logos.

Cabe ahora preguntarnos si este nuevo atributo, "siente", nos permite mantener la interpretación que hasta ahora hemos dado del témino "lógos"del fragmento 50, la cual ha sido ratificada a la luz de los otros fragmentos.

¿El logos "siente" es otro que el "reuniente" ? ¿Es otro que el develante? ¿Qué acentúa Heráclito aquí? ¿El toude, el éontos o el aiéi? ¿O los acentúa a los 
tres? No hay nunca una sílada de más en los textos del efesio, así que conviene que no separemos la expresión toúde éontos aiel, y que, nos fijemos en cada uno de sus elementos.

\section{El lógos aieì eón como tò proton (Fr. 1)}

Heráclito está hablando aquí del ser del lógos o del ser que es el lógos? Parecería que se refiriese a este último, aunque en un cierto sentido coinciden. Dice de él que es un "ser-siempre". Esta afirmación excede de la capacidad experencial humana. El hombre puede pronunciarla sólo si se refiere a lo divino o a algo que, de algún modo, se le asemeje. De las cosas, el hombre puede decir que "son", pero no que "son siempre", en cuanto su ser está constreñido dentro de lindes precisos. No así el ser del lógos, que se extiende antes y después, arriba y abajo, más aquí y más allá. Es, la suya, una verdadera irrupción que hace que el hombre se confronte con un ámbito de realidades inasibles, $Y$, sin embargo, más concretas y certeras que todas las otras de las cuales puede dar cuenta: una irrupción en un punto inextenso no anclado en superficie alguna. Pensar el "siempre" es por cierto un desafío para nosotros, criaturas del ahora. ¿Qué significa "siempre"? Visto desde el ahora, el "siempre" se extiende en el tiempo hacia atrás y hacia adelante con respecto a ese "ahora" en que estamos intentando pensarlo; en una y otra direccion, indefinitamente: hasta antes de que hubiera tiempo; hasta cuando ya no haya tiempo, si es que esto sucedió o llegare a suceder alguna vez. Al pensarlo lo reducimos, y ya no es "siempre", porque no podemos pensarlo sin acotarlo dentro de ciertos límites, por vaporosos y difuminados que sean. Pero ésta no es la única manera de pensar el siempre. El siempre de Zubiri, por ejemplo, nos arranca de la secuencia que avanza del ahora al después, y nos sitúa fuera y por encima de ella. Se constituye como "fundamento unitario anterior al despliegue de lo multiple" (Zubiri, 1944, p. 121 seq.); justamente como tò prôton. "Siempre" no significa, para Zubiri, "que perdura a través del tiempo"; sino, "que está sobre el tiempo"; "ciertamente no separado de él, pero sí abrazándolo y absorbiéndolo como principio y supuesto suyo". "El tiempo es un momento del acontecer radical". "El siempre es el esquema que nos lleva a superar el sentido del ser como acontecer y abre ante nuestros ojos la ousía como realidad". "El siempre como esquema de la ousía, no significa primariamente una idéntica permanencia en el fondo del acontecer, sino tan sólo una elevación hacia el principio que lo hace posible"16.

El lógos aiel eón de Heráclito es to prôton a la manera del siempre de Zubiri: se empina "hacia el principio que hace posible el acontecer" entendido como "el despliegue del haber propio y peculiar de la cosa" hasta coincidir con él.

Otra interrogante nos atormenta: ¿Podemos pensar al siempre vaciado de ser? ¿Podemos pensar un siempre-nada? Hoy, claro está, un filósofo puede pensar "la nada" ; pero era eso posible, podría haber sido posible para un griego del sexto o quinto siglo antes de Cristo; cuando aún el mito se resistía a ceder ante la razón; cuando recién se estaba empezando a pensar el ser? El no-ser sólo puede pensarse desde el ser y dentro de él. Habitándolo. Y es también desde el ser y dentro de él como puede pensarse el siempre. Si Heráclito hubiese pensado el ser y el no-ser por separado, y yuxtapuestos, el siempre habría podido en algún momento dejar de ser el-siempre-del-ser. Los momentos del no-ser son los momentos de la nada, 
los momentos del nunca. Si los hubiese, o si Heráclito los hubiese pensado, entonces los momentos del ser serían a cada instante acosados por los momentos del no-ser. Ya no habría siempre. Pero no es así: hay ser, y Heráclito puede atribuirlo, - si es que efectivamente lo atribuye -, a algo para él concreto, al lógos del cual puede decir, indicándolo, "éste". Este del cual recién hice mención ; éste del cual hace poco hice experiencia, éste al que descubrí en su verdad; éste al que Uds. no ven, no oyen, no entienden, porque son ciegos, sordos y necios; éste conforme al cual lo que nos rodea es. Como podemos constatar, eón y aiel son inseparables.

\section{El lógos hèn pánta (Fr.50)}

Veamos ahora como esos dos términos aiéi y eón se enlazan y adhieren al lógos. Volvamos a ponernos la pregunta: ¿Qué es el lógos? Si el lógos fuese simplemente "palabra", y palabra común y corriente, sería por cierto impossible decir de él que "es siempre". Pero ya hemos visto que lógos no es sólo "palabra", ni sólo "discurso", ni sólo "expresión". De ser tal, deberíamos pensar que conserva el sentido fuerte de mŷthos. Y podríamos hacerlo. Pero Heráclito parece querer desvincularse del mito y buscar más bién la intensidad y el vigor en la palabra sentida en su sustancialidad a-mítica ; forzándola, doblegándola, sometiéndola a la viveza de su pensamiento. Y hemos visto como la raíz de légo, a la que lógos se remite, indica juntamente el "unir" y el "decir". Es difícil ahora establecer cúal de estos dos sentidos fue originariamente anterior (17). Lo más probable es que no se pueda hablar, para ninguno de ellos, de anterioridad o posterioridad, y que los dos sentidos "se deban" uno al otro. El lógos como fuerza unificante lleva a con-stituir y a manifestar, à prendre à la main y a "decir" lo que ha unificado y puesto en el ser, que allí se muestra como un hólon, como algo no disperso y de fuerte raigambre. Y por otro lado, el lógos como fuerza develante lleva a recoger todos los "indicios" (18) que juntos forman el "cuerpo" de lo develado.

Si es asi. debemos preguntarnos de quién o de qué puede decirse que reúne o que devela, y qué es lo que ese alguien o ese algo reúne y devela. No queda sino pensar en el Ser como "Uno-Todo", por un lado concentrado en su ser unificante y develante, por el otro desplegado en su ser reunido y develado. Porque esto parece ser, en efecto, el lógos como "siente": lo uniente que encuentra dentro de sí aquello sobre lo cual habrá de ejercer su poder unitivo, lo develante que encuentra dentro de sí aquello que se le ofrece para ser develado. El "salir fuera" no es sino la modalidad propia de su abrirse, y el "volver a entrar", la modalidad propia de su recogerse. En el lógos no hay dicotomía: se desglosa en una díada dotada de un ritmo interno que conjuga dos vertientes que son prescisamente la instancia del recogimento y la instancia de la mostración. ¿De otro modo cómo podría ser "el siempre siente"? Su mostrarse es un "emerger", su recogerse un "ponerse" (a la manera del sol) y un entrar bajo el amparo de sí mismo. Y por otro lado, su mostrar es un mostrarse y su recoger un recogerse. En eso consiste el Ser, entendido dinámicamente: perenne renovación de sí en perfecta continuidad y armonía, phýsis que brota y se cela en el doble movimiento de la emergencia (anatolé) y del ocaso (dýsis).

La presencia de los pánta en el lógos-ser anida en la semática unitiva del étimo, que permite al lógos acogerlos sin dejar de ser lo que es: esseidad unificante. 
Recordemos las palabras de Heidegger: "ho logos sert à nommer ce qui rassemble toute chose présente dans. la présence et l'y laisse devant nous. Ho Lógos désigne ce en quoi la présence des choses présentes se produit. La présence des choses présentes se disait chez les Grecs to eón, c'est-a-dire tó eînai tôn ontôn (...); nous disont l'être de l'étant. (...); qu'au temps des Grecs, l'être de l'étant soit devenu la chose digne d'être pensée, ce fait est le début de l'Occident ..." (Heidegger, 1958, p. 275).

\section{Notas}

1- La implicacíon se ve de manera más clara en el compuesto alégo, provisto de un alfa intensivo y que significa: "tomo bajo mis cuidados, me ocupo de, soy solícito, estoy atento a".

2- Se ha pensado a una posible derivación de xynós del radical del verbo xyô, "trocar", pero el sentido más propio de xyô es "raspar, frotar", y el parentesco aparece algo forzado.

3- Es la opinión de Heidegger (Heidegger-Fink, 1986, p.37): "Lo xynón supone un problema especialmente enmarañado porque en su interior juega lo $x y n$ nóoi"; y también la de Jaeger (Jaeger, 1980, p.117): "... el lógos es lo que es común a todas las cosas (xynón pâsi). Su órgano es la mente o el nóos. Hablar con la mente (xyn nóoi) no significa para Heráclito otra cosa que "con lo comán (xynói)".

4- No parece haber dudas sobre el término al cual se refiere el pronombre relativo hos. Es opinión común que ese término sea lógos, y en ello convienen también aquellos estudiosos que, como Marcovich, consideran añadida por Marco Antonio, autor de la cita, la expresión: lógoi tôi tà dioikoûnti.

5- Fr. 10 (sympherómenon), fr. 51 (symphéretai), fr. 8 (symphéron).

6- Ya vimos que hay en homós la idea de unión, igualdad, semejanza, mismidad. Hómilos significa: "reunión de muchas personas, muchedumbre". Homiléo significa: "encontrarse con", y el encuentro puede ser amigable u hostil; por eso puede asumir el sentido de "tener trato o contacto con, ocuparse de, acompañar a", pero también de "luchar contra alguien".

7- Fr. 17 ou gàr phronéousi toiauta pollơ hokósoi enkyréousin, oudé mathóntes ginóskousin, heoutoîsi de dokéousi: "Muchos no comprenden las cosas con las cuales tropiezan; no las conocen ni siquiera después de haberlas aprendido; les parece, sin embargo, conocerlas".

8- De anima, 416a 9-10 y 15-17: dokêi dé tisin he tôu pyrós phýsis haplôs aitía tês trophês kai tês auxéseos eînai (...) he mèn gàr tôu pyrós auxesis eî́s ápeiron (...), tôn dè phsei synistamenôn pánton estì péras kaì lógos megethous tè kai auxéseos.

Creen algunos que la naturaleza del fuego es evidentemente causa de la nutrición y del crecimiento (...); en efecto el acrecentamiento del fuego es al infinito (...), mientras para todas las cosas que se forman por naturaleza hay un límite y una medida de grandeza y de crecimiento.

De anima, 405a - 5: hóthen édoxé tisi pyr kai gàr toâto leptomeréstatón te kai málista tôn stoikhéion asómaton, éti de kinêitai te kai kinêi tà àlla prótos.

Por lo cual creyeron que el alma era fuego, y en efecto (éste) es compuesto de partes pequeñísimas y es el más incorpóreo entre todos los elementos; además se mueve por sí sólo y mueve prinscipalmente todo lo otro. Cfr. tanbién: De partibus 
animalium, 652b 7-9; Metereologica 354b 33ss. y Simplicio: Physika 24, 6 y 36, 8; citados por Mondolfo y Tarán en Eraclito. Testemonianze e Imitazioni, 1979, pp.142143 , nota 178.

9- De anima, 405a - 24: tèn arkhèn êinai phesì psykhén eíper tèn anathymiasin, ex hês tálla synistesin.

10- Tertuliano: De anima 14,5: (...) ubique ipsa, velut flatus in calamo per cavernas (...) . Citado por Marcovith en: Eraclito Frammenti, 1978 p.396. Cfr. Diels. Doxographi Graect, p.209ss.

11- Ese doble movimiento que se asemeja a una escansión musical, se encuentra también en al fr. 91 en la cita de Plutarco: De E apud Delfos 18,392 B: skídnesi kaì pálin synagế, mallon dè oudé pálin oud'hýsteronall'háma synistatai kai apoleipei, kaì próseisi kai ápeisi. Se esparce y nuevo se recoge; o mejor, ni de nuevo ni después, sino al mismo tiempo se reúne y se separa, se acerca y se aleja. Marcovich, 1978, p.143.

12- Fr. A16 Sexto Empirico, Adversus mathematicos VII 129: (...) mónes tês katà anapnoén prosphýseos sozoménes hoionéi tínos rizes (...). ... conservándose una sóla juntura gracias a la respiracíon, como una suerte de raíz... . Mondolfo Tarán, 1972, p.146.

13- Fr.114: (...) tréphontai gàr pántes hoi anthropeioi nómoi hypd hends, tôu theiou, kratéei gar tosoaton hokóson ethélei kal exarkéei pâsi kai periginetai. ... se nutren, en efecto, todas las leyes humanas de una sola, la divina; domina ella, en verdad, tanto cuanto quiere; basta todas y (siempre) hay más.

14- Hemos preferido una versión no tradicional, interpretando tò prôton en un sentido fuerte, como "lo principal", en función de complemento predicativo, en lugar de verlo como un simple acusativo adverbial. Nos parece ver en to prôton la ratificación de la bella definición del lógos como "el siempre siente" que encabeza el fragmento. Uma tal definición sería en verdad inaccesible sin la develación del mismo lógos eón aiel. Lo "principal" no puede ser otro que el Ser, y si el lógos se revela como tal, como to prôton, quiere decir que tras de el se oculta y devela precisamente el Ser.

15- Si el fragmento 1 es al comienzo del libro de Heráclito, (aunque la existencia misma del libro es bastante discutida), el toude conserva algo del asombro ante una presencia que el filósofo ha advertido, y de la cual quiere hacer partícipes a otros. La partícula dé, separada primero y luego unida al tổ, produce una asonancia agradable para el oído, acentuada por el juego de los sonidos 0 , u, e, que se da en las primeras cinco palabras del fragmento; $y$, no siguiendo a ningún mén anterior, ni iniciando una serie, parece tener el valor del $d \dot{e}$ al cual originariamente se remonta, y podría traducirse con la exclamación "y he aquí que ...". Une, en efecto, a su valor adversativo-copulativo un matiz de sorpresa, que delata la inmediatez de algo fuera de lo común que ha acontecido en la esfera de lo sensible. Ese algo es la develación del logos como Ser. Si en cambio el fragmento 50 originariamente precedía al 1, entonces tonde tiene un valor indicativo y quiere decir simplemente: "éste del cual hablábamos recién".

Cualquiera que sea la interpretación que escojamos, la voz, pronunciando esa primera línea del fragmento 1 , vuela hacia el éontos aiéi que "dice" la naturaleza del lógos, su ser siempre siente.

16- Para Zubiri ousía y ael son lo mismo; es decir: los griegos habrían, a su juicio, llamado inicialmente ael eón ló que después tomó el nombre de ousía. (Zubiri 1944, p.122 y 124). 
17- En latín la antiquísima fórmula: senatus dicere, significaba "convocar al senado llamando por su nombre a los senadores uno por uno". No nos quedan ejemplos similares en griego, pero creemos que no es arbitrario admitir que se hayan empleado expresiones análogas en relación a circunstancias análogas.

18- La palabra indicio significa "noticia", indicación", y procede de indico, "denunciar, descubrir, mostrar"; es decir, es aquello que da a conocer cada nota de lo "indicado".

\section{Referencias Bibliográficas}

\section{OBRAS DE REFERENCLA}

CHANTRAINE, P. Dictionnaire étimologique de la langue grecque. Paris: Klincksieck,1968. 4v..

ERNOUT-MEILLET . P. Dictionnaire étimologique de la langue latine. Paris: Klincksieck,1959.

LIDDEL, H. G. \& SCOTT, R. A Greek English Lexicon. Revised and augmented throughout by H. S. Jones. Oxford: Clarendon Press, 1968 [reprinted 1985].

\section{OBRAS GENERALES Y ESPECIFICAS}

DISANDRO, C. Tránsito del mythos al logos. La Plata: Hostería Volante, 1969.

GUTHRIE, W.K.C. História de la Filosofía griega. Madrid: Gredos, 1984.

HEIDEGGER, M. Lógos (Héraclite, Fragment 50). In: - . Essais e Conférences. Traduit de l'allemand par André Préan, Paris: Gallimard, 1958, p. 249-78.

HEIDEGGER, M. \& FINK, E.. Heraclito. Barcelona: Ariel, 1988

JAEGER, W. La Teología de los primeros filósofos griegos. México: Fondo de Cultura Económica, 1980.

SHIPTON, K,M.W. Heraclitus Fr.10: a musical interpretation. Phronesis, Assen, v. 30, n. 2, 1985.

SNELL, B . La cultura greca e le origini del pensiero europeo. Torino: Einaudi, 1963.

ZUBIRI, X.. Naturaleza, Historias, Dios. Madrid, 1944

\section{FUENTES}

ARISTOTELIS . De Anima. Oxford Classical Texts. Oxonii: E Typographeo Clarendoniano.

DIELS, H . Doxographi Graeci. Berolini: W. Gruyter, 1958.

DIELS-KRANZ. Die Fragmente der Vorsokratiker. Zurich-Berlin: Weidmannsche Ver_lagsbuchandlung, 1964. 3v.

ERACLITO . Frammenti. A cura di Miroslav Marcovich. Firenze: La Nuova Italia, 1978.

ERACLITO . Testimonianze e Imitazioni. A cura di Rodolfo Mondolfo e Leonardo Tarán. Firenze: La Nuova Italia, 1972. 
GRAMMATICO, G. Une approche du logos heráclitéen. Classica, São Paulo, 5/6, 11-27, 1992/1993.

RESUME: D'abord, on analyse les sens du mot lógos, dans le cadre de la recherche du lógos heráclitéen. Celui-ci semble être, d'après son étymologie, la cause, le ressemblant et la révélation, et coïncider avec l'Etre. II faut, cependant, ratifier, au moyen de plusieurs fragments-clés, la vérité de telles affirmations. On considère en tant que "clé" les fragments 2, 72, 123, 115, 45, 1. Dans ces fragments, on montre l'adjectif xynós, "commun"; la phrase hó málista homiloasi, "celui avec lequel principalement les hommes ont rapport": le nom phýsis, "nature"; les attributs auxôn, "qui s'augmente", et bathýs, "profond"; et le binôme hèn-pánta, "un-tout". Examinées et interpretées toutes ces expressions, elles apportent des auguments qui confirment la justesse de la hypothèse initiale. MOTS CLÉS: Logos, Héraclite, philosofie grecque, Grèce. 